\title{
RULE-BASED EXPERT SYSTEM FOR DETECTION OF COFFEE RUST WARNINGS IN COLOMBIAN CROPS
}

\author{
Authors: \\ Edwar Javier Girón Buitrón ${ }^{1,}$ \\ David Camilo Corrales ${ }^{1}$ \\ Jacques Avelino² \\ Jose Antonio Iglesias ${ }^{3}$ \\ Juan Carlos Corrales ${ }^{1}$ \\ ${ }^{1}$ Department of Telematics Engineering, Engineering Telematics Group, University of \\ Cauca, Popayán, Colombia. \\ ${ }^{2}$ CATIE, Program of Sustainable Agriculture and Agroforestry, Turrialba, Costa Rica; CIRAD, \\ UR Bioagresseurs, TA A-106-Avenue Agropolis, Montpellier, France; IICA, AP 55, \\ Coronado, San José, Costa Rica. \\ ${ }^{3}$ Computer Science and Engineering Department, CAOS Research Group, Carlos III \\ University of Madrid (UC3M). \\ Emails: \{ edwardgb,dcorrales,jcorral \}@unicauca.edu.co. http://www.unicauca.edu.co. \\ jiglesia.at.inf.uc3m.es https://www.uc3m.es
}

\section{Highlights}

- A set of rules are created based on weather attributes and area properties of crops.

- An expert system is proposed to detect of coffee rust levels in Colombian coffee crops.

- Results showed that attributes associated with foliation in the crops must be includes in the rules used by the expert system.

\section{Keywords}

Decision support system, crops, disease, agriculture, Hemileia vastatrix.

\section{Abstract}

The coffee rust is a devastating disease that causes large economic losses across the world. The severity of this disease changes over time so the farmers are not fully aware of the economic importance of the rust disease in the coffee crops. From a computational science perspective, several investigations have been proposed to decrease the effects caused by the coffee rust appearance. One of the most important proposals is the use of expert systems. This paper proposes a novel rule-based expert system in which the knowledge base contains the variables and the set of rules that define the problem. The Buchanan methodology is used to design the proposed system. Experiment results present an average accuracy of $66,67 \%$ to detect a correct warning of coffee rust levels. 